\title{
Zeolite usage as source of silica to produce cordierite in $\mathrm{MgO}-\mathrm{Al}_{2} \mathrm{O}_{3}-\mathrm{SiO}_{2}$ system
}

\author{
Tuğba Tunç PARLAK*, A. Şükran DEMIRKIRAN \\ Department of Metallurgical and Materials Engineering, Faculty of Engineering, \\ Sakarya University, Esentepe Campus, 54187, Sakarya, Turkey \\ Received: March 1, 2018; Revised: June 25, 2018; Accepted: June 29, 2018 \\ (C) The Author(s) 2018. This article is published with open access at Springerlink.com
}

\begin{abstract}
In this study, natural zeolite was used as source of silica to produce cordierite. $\mathrm{MgO}$ and $\mathrm{Al}_{2} \mathrm{O}_{3}$ were added to zeolite to obtain the cordierite stoichiometry. Mixture of these raw materials was mechanically activated for different durations. The mechanically activated powder mixture was characterized using XRD, DSC, SEM, specific surface area, and particle size analyzer. The pycnometer method was used to measure the densities of mechanically activated powder mixtures. Mechanically activated for $60 \mathrm{~min}$ powder mixture was sintered at $1150-1350{ }^{\circ} \mathrm{C}$ for $1 \mathrm{~h}$. The sintering behavior of the samples was determined by measuring the linear shrinkage, density, and apparent porosity. The phases in the sintered samples were identified by XRD. Cordierite and spinel phases were detected for sintered at a temperature higher than $1150{ }^{\circ} \mathrm{C}$ but corundum accompanied to cordierite and spinel at $1150{ }^{\circ} \mathrm{C}$. The microstructure of the samples was examined using both SEM and AFM. The sintering behavior and microstructural properties of the samples changed with an increase in the sintering temperature. As the apparent porosity increased with increasing sintering temperature, linear shrinkage and density values decreased. Density values were determined as 2.31-2.69 g/ $\mathrm{cm}^{3}$ depending on the temperature. The grains coarsened at higher temperature and the average grain size depending on the temperature was 1.34-1.96 $\mu \mathrm{m}$. From the results optimum sintering temperature was determined as $1250{ }^{\circ} \mathrm{C}$. Dense material was produced at a temperature as low as $1250{ }^{\circ} \mathrm{C}$ using zeolite as raw material.
\end{abstract}

Keywords: mechanical activation; sintering; zeolite; cordierite

\section{Introduction}

Cordierite cited as refractory material for industrial applications has $2 \mathrm{MgO} \cdot 2 \mathrm{Al}_{2} \mathrm{O}_{3} \cdot 5 \mathrm{SiO}_{2}$ chemical composition [1,2]. Cordierite phase is firstly discovered by Rankin and Merwin in their studies on the phase diagram of $\mathrm{MgO}-\mathrm{Al}_{2} \mathrm{O}_{3}-\mathrm{SiO}_{2}$ [3-5]. The simplified

* Corresponding author.

E-mail: ttunc@sakarya.edu.tr composition of pure cordierite ceramic is approximately $14 \% \mathrm{MgO}, 35 \% \mathrm{Al}_{2} \mathrm{O}_{3}$, and $51 \% \mathrm{SiO}_{2}$ by weight $[5,6]$. When percentages of oxides are marked on the phase diagram of $\mathrm{MgO}-\mathrm{Al}_{2} \mathrm{O}_{3}-\mathrm{SiO}_{2}$, this compound stays out of cordierite area. This phenomenon means that cordierite is an incongruent phase. As the primer crystallization area of cordierite is surrounded by five different phase transformations, it is difficult to produce single phase cordierite due to the limitation of sintering interval of $25{ }^{\circ} \mathrm{C}$ below from its melting point of $1455{ }^{\circ} \mathrm{C}$ [5]. 
Cordierite has three polymorphs as, " $\alpha$ " also known as indialite, " $\beta$ ", and " $\mu$ " [7-9]. There are two types of cordierite which were distinguished as porous and dense [6]. Besides, cordierite is widely used in glass-ceramic compositions [2]. Cordierite and cordierite-based glass ceramics are promising materials for industrial applications because of their low dielectric constant, high resistivity, elevated thermal and chemical stability, very low thermal expansion coefficient, and excellent thermal shock resistance resulting from its very low thermal expansion, high thermal conductivity, high refractoriness, and fine mechanical properties [7,10-14].

Because of its features, cordierite finds usage area as support for catalytic converter [15,16], filters [2], refractor coating on metals, integrated circuit board, electrical porcelains [7], heater element [4,8], electrical [8], thermal [2], and sound isolation, microwave and electromagnetic wave absorbent [4].

The most common production way of cordierite is solid state sintering of $\mathrm{SiO}_{2}, \mathrm{Al}_{2} \mathrm{O}_{3}$, and $\mathrm{MgO}$ mixture that is prepared according to cordierite stoichiometry at high temperatures [17]. Low sintering temperature can be obtained by using additives or preparing fine grained powders [18]. It is possible to decrease the sintering temperature by using additives, but usage temperature also decreases correspondingly [19].

Mechanical activation is another process that could be used for decreasing sintering temperature [14]. In this process, particle size [20] and reaction temperature are decreased and degree of completion of solid state reaction is increased as well [21]. Mechanical activation process is important as it creates deformations or changes in the structure. These changes modify the phases which occur in the structure [22]. Particle size and surface area are often correlated with chemical reactivity, packing, catalytic behavior, adsorption, contamination, and even compaction and sintering. For example, if the surface area increases, the particles exhibit less efficient flow and packing. In addition, as the mean particle size increases, sintering effect degrades [23]. Balaz [20] stated that processes under the influence of mechanical activation can be subdivided into primary and secondary ones. Generally, the primary processes such as increase of internal and surface energy, increase of surface area, decrease of the coherence energy of solids increase the reactivity of the substance. The secondary processes such as aggregation, adsorption, and recrystallization take place spontaneously in activated systems and may appear even during milling or after milling, a gradual deterioration is observed. During this process, three stages can be clearly distinguished: the Rittinger stage (a), in which the interaction of particles can be neglected; the aggregation stage (b), in which the new surface area produced is not proportional to the energy input because of particle interaction (aggregation); and the agglomeration stage (c), in which the increase of dispersion first drops to a negligible value and then stops altogether [20]. This process has been used in production of high technology materials from simple to complex powder systems for modification of physicochemical features [24].

In literature, starting materials for cordierite production are presented as magnesium compounds and kaolinite mixture; alkaline-earth alumina silicate glass, kaolinite, alumina and magnesite; talc, calcined alumina and fly ash; kaolinite, talc, silica and alumina; talc, kaolinitic clay and gibbsite; kaolinite, talc and magnesium oxide; talc, kaolinite, silica, sepiolite and feldispar; kaolinite and talc [25]. However, there is no study about cordierite ceramic produced from zeolite, so far [26].

Zeolites are known as alumina silicate mineral found in the nature [27]. Tetrahedral of silicon-oxygen $\left(\mathrm{SiO}_{4}\right)$ and aluminum-oxygen $\left(\mathrm{AlO}_{4}\right)$ units repeat themselves in the three-dimensional network [28]. In their structure connected spaces, water molecules [29] and exchangeable alkaline or alkaline-earth charges such as $\mathrm{Na}^{+}, \mathrm{K}^{+}, \mathrm{Ca}^{2+}$, and $\mathrm{Mg}^{2+}$ situated in two-dimensional channels [30]. Present cations that bonded to aluminum by electrostatic force, are easily exchangeable with other metal cations to maintain the natural neutralization [31].

The aim of this study is to investigate the feasibility of using zeolite for cordierite manufacturing and determine the effect of mechanical activation and sintering temperature on the phase composition, linear shrinkage, density, and apparent porosity.

\section{Materials and methods}

\section{1 Characterization and preparation of the powder mixture}

The starting materials used in this study were $\mathrm{Al}_{2} \mathrm{O}_{3}$ (Alfa Aesar, 99.9\%), MgO (Alfa Aesar, 99\%), and zeolite. Clinoptilolite which is natural type of zeolite was selected as source of silica to produce cordierite in $\mathrm{MgO}-\mathrm{Al}_{2} \mathrm{O}_{3}-\mathrm{SiO}_{2}$ ternary system. The chemical composition and XRD pattern of zeolite supplied from Etibank/Turkey, are presented in Table 1 and Fig. 1, 
Table 1 Chemical composition of zeolite used as raw material (Unit: $w t \%)$

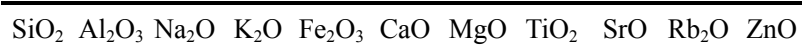

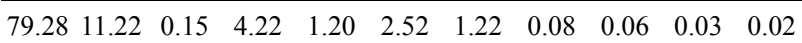

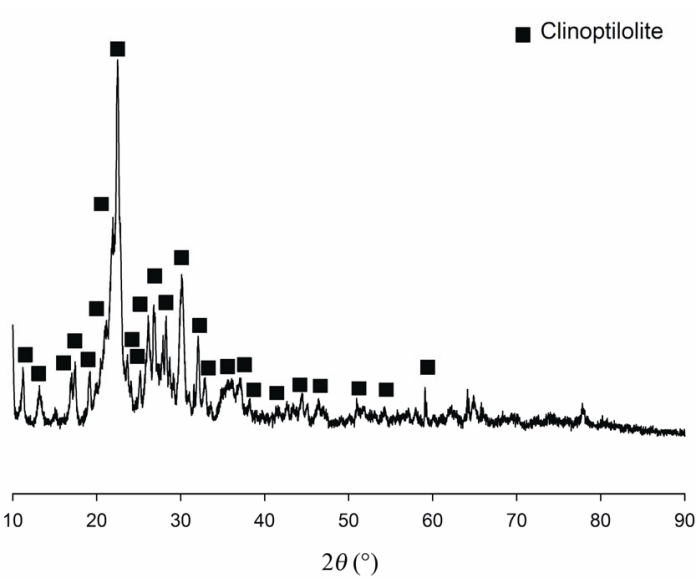

Fig. 1 XRD analysis of provided zeolite sample from Eti Mine Company, Turkey.

respectively. The powder mixture that consists of zeolite (clinoptilolite), $\mathrm{Al}_{2} \mathrm{O}_{3}$, and $\mathrm{MgO}$ was prepared according to cordierite stoichiometry and mechanically activated by Planetary Mono Mill Pulverisette 6 . Grinding bowl that has $250 \mathrm{~mL}$ capacity and balls that have $8.14 \mathrm{~g}$ weight and $10 \mathrm{~mm}$ diameter are made of tungsten carbide. High energy dry milling was performed in atmospheric conditions, for $5,15,30,60$, and $120 \mathrm{~min}$ at $600 \mathrm{rpm}$. Ball-to-mass ratio was kept constant at 20 . Then, the mechanically activated powder mixture was characterized by several techniques.

The phase analyses of the mechanically activated powders were realized using X-ray diffraction (XRD) analysis with a Rigaku D/MAX 220 PC diffractometer operating with $\mathrm{Cu} \mathrm{K \alpha}(\lambda=1.54056 \AA)$ radiation.

Amorphization degree of each phase found within the powder mixture was separately calculated according to XRD data by the following Eq. (1):

$$
A \%=\left(1-\frac{I_{\mathrm{X}} \cdot B_{0}}{I_{0} \cdot B_{\mathrm{X}}}\right) \cdot 100
$$

where $B_{0}$ and $B_{\mathrm{X}}$ denote the background values of the diffraction peaks for non-activated (reference) sample and activated sample while $I_{0}$ and $I_{\mathrm{X}}$ are integral intensities of the diffraction peaks for non-activated (reference) sample and activated sample, respectively [20].

TA Instruments SDT Q600 equipment was used to perform differential scanning calorimetry (DSC) experiments. The powder mixture mechanically activated for 30 and $60 \mathrm{~min}$ was heated to $1350{ }^{\circ} \mathrm{C}$ under air atmosphere at heating rate of $10{ }^{\circ} \mathrm{C} / \mathrm{min}$.

The average particle size, particle size distribution, and the nature of agglomerates were determined using a particle size analyzer (Microtrac S3500). The specific surface area of powders was measured by Micromeritics Gemini 2360 Surface Area Analyzer. The morphology of the powder mixture was examined by scanning electron microscopy (SEM, JEOL JSM 6060 LV). The pycnometer method was used to measure the density of the powders.

\section{2 Production and characterization of the samples}

For production of the samples, water $(7 \mathrm{wt} \%)$ was added as binder to the activated powder mixture and disc samples ( $\varnothing=16 \mathrm{~mm}$, with $3 \mathrm{~mm}$ thickness) were shaped by uniaxial dry pressing with pressing pressure of 3.5 tones. Compacted samples were dried at $110{ }^{\circ} \mathrm{C}$ for $24 \mathrm{~h}$ and sintered in electrical furnace at 1150, 1200, 1250, 1300 , and $1350{ }^{\circ} \mathrm{C}$ with $10{ }^{\circ} \mathrm{C} / \mathrm{min}$ heating rate for $1 \mathrm{~h}$. The samples were cooled to room temperature in the furnace.

The sintering behavior of the samples was evaluated by measuring the linear shrinkage, water absorption, density, and apparent porosity. The density of the sintered specimens was determined by the Archimedes principle. Phase analysis, examination of microstructure, and grain size measurement were realized by Rigaku Ultima X-ray diffractometer with $\mathrm{Cu} \mathrm{K} \alpha(\lambda=1.54056 \AA)$ radiation, JEOL JSM 6060 LV scanning electron microscope and Quesant AFM at 3-Hz scanning rate, respectively.

For microstructural examination, firstly, sintered samples were prepared via classical ceramography techniques. After the polishing process, the samples were etched with the HF solution of $10 \%$ during $90 \mathrm{~s}$. One of the simplest techniques to estimate an average grain size is linear intercept method. Therefore, linear intercept method was used for grain size measurement. Random ten straight lines as vertical, horizontal, and diagonal were drawn upon the AFM images. The number of grain boundaries intersecting the line was counted, and the mean intercept length was calculated according to Eq. (2):

$$
L=\frac{L_{\mathrm{T}}}{M \cdot N}
$$

where $L_{\mathrm{T}}$ is the total line length, $M$ is the magnification, $N$ is the total number of grain boundary intersections, and $L$ is the mean intercept length [32]. Magnification 
value was taken " 1 " in Eq. (2) as the image was taken at real size at AFM.

The average grain size $G$ was obtained by Mendelson's method given as [33]:

$$
G=1.56 L
$$

\section{Results and discussion}

\section{1 Characterization of mechanically activated powder mixture}

The XRD patterns of mechanically activated $\mathrm{MgO}$ / $\mathrm{Al}_{2} \mathrm{O}_{3}$ /zeolite powder mixture for different milling durations are given in Fig. 2. Obtained XRD patterns allowed the observation of structural changes occurred within powder mixture that prepared by planetary highenergy ball mill. Periclase, corundum, and zeolite phases were detected within activated mixture. However, any new phase formation was not observed and in respect to increased milling time, intensity of the peaks shortened and/or disappeared. In addition, amorphization took place, and an increase in amorphization degree was observed with prolonged activation time. Balaz [20] stated that mechanical activation can be regarded as a multi-step process with changes in the energetic parameters and the amount of accumulated energy of solids in each step. The four processes, namely, the accumulation of defects, amorphization, the formation of metastable polymorphous forms, and chemical reaction, are united by the term mechanical activation. Balaz described that the amorphization is in fact a highly distorted periodicity of lattice elements, and it is often characterized as a short-range order in contrast to the long order of a fully crystalline structure. During high-energy milling, the

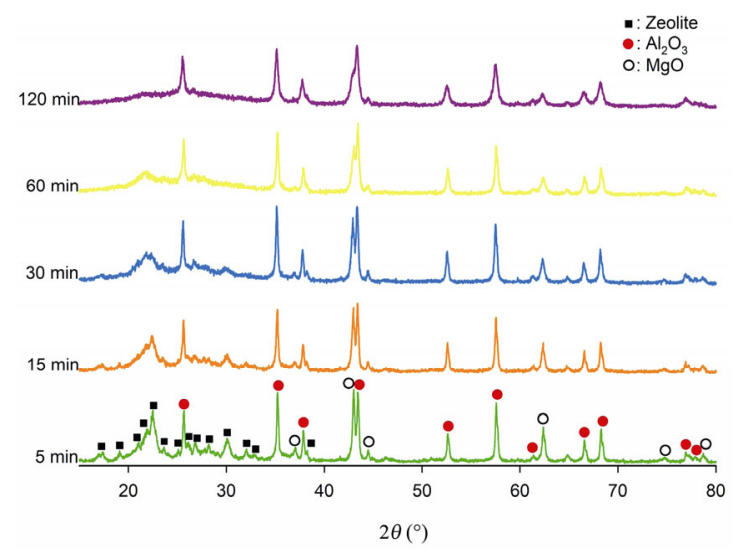

Fig. 2 XRD analysis of mechanically activated powder mixture for $5,15,30,60$, and $120 \mathrm{~min}$. size of crystals decreases to some critical values. Further energy supply to these crystals of limiting size causes further deformation of crystals, energy accumulation in the volume or at the surface of crystals, and subsequently amorphization. In addition, Tromans and Meech [34] expressed that formation of meta-stable in other words amorphous phase was indicated by line broadening and disappearance of reflections at XRD that means alteration of long-range lattice periodicity and creation of large number of dislocation.

Amorphization degree of each phase found within the powder mixture was separately calculated and presented in Fig. 3. It was seen that amorphization phenomenon mostly occurred in zeolite phase and this tendency increased with increment in milling time. As understood, while alteration of zeolite structure was easily achieved, alteration of $\mathrm{MgO}$ and $\mathrm{Al}_{2} \mathrm{O}_{3}$ was harder. As known, zeolites are microporous, crystalline, hydrated aluminosilicates composed of $\mathrm{TO}_{4}$ tetrahedra $(\mathrm{T}=\mathrm{Si}, \mathrm{Al})$ with $\mathrm{O}$ atoms connecting neighboring tetrahedra, in which the substitution of silicon by aluminum in the framework positions leaves a negative charge behind; in turn, this charge may be compensated by alkali or alkaline earth cations [35]. The shorten and/or disappeared diffraction peaks of zeolite can be attributed to: (1) the breaking of external $\mathrm{Si}-\mathrm{O}-\mathrm{Si}$ bonds and $\mathrm{Si}-\mathrm{O}-\mathrm{Al}$ bonds of zeolite crystal and the collapse of the original crystalline structure under the effect of intensive mechanical forces; (2) the reduction of the zeolite particle size $[35,36]$. After $1 \mathrm{~h}$ milling time, amorphization degree of zeolite was $100 \%$.

Figure 4 illustrates the DSC curves of the powder mixture mechanically activated at two different durations. Both DSC curves revealed two endothermic peaks and two exothermic peaks. The endothermic peak at around $140{ }^{\circ} \mathrm{C}$ indicates the presence of free water and the weight change takes place due to the loss of the physically adsorbed water at around this temperature.

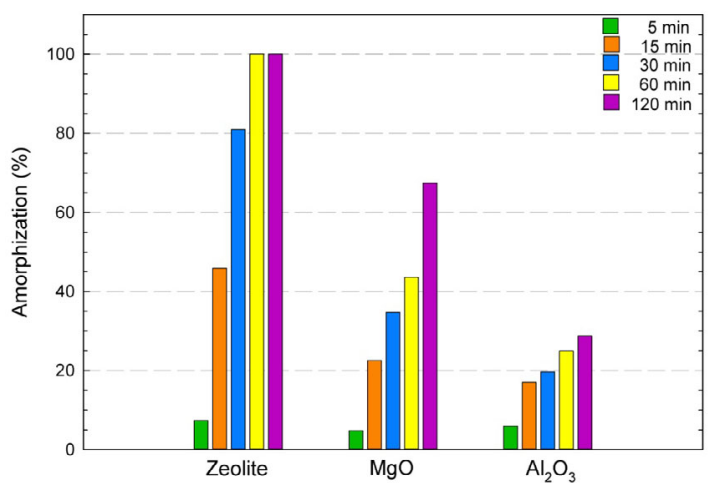

Fig. 3 Amorphization degree diagram of the phases. 


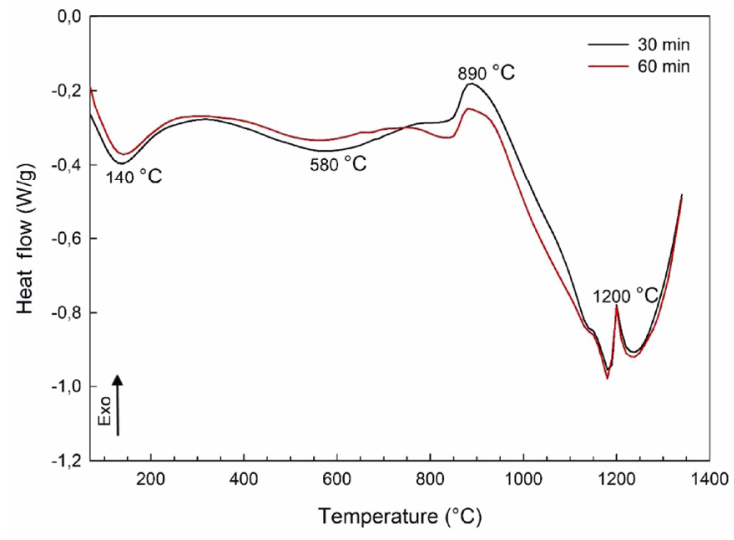

Fig. 4 DSC analysis of mechanically activated powder mixture for 30 and $60 \mathrm{~min}$.

The large endothermic peak at around $580{ }^{\circ} \mathrm{C}$ results from dehydroxylation of zeolite having molecular water. The first exothermic peak at $890{ }^{\circ} \mathrm{C}$ was attributed to formation of spinel phase $\left(\mathrm{MgAl}_{2} \mathrm{O}_{4}\right)$. The exothermic peak at $1065{ }^{\circ} \mathrm{C}$ of $\mathrm{MgAl}_{2} \mathrm{O}_{4}$ spinel phase was reported by Su et al. [37]. The second exothermic peak at $1200{ }^{\circ} \mathrm{C}$ corresponds to the formation of $\alpha$-cordierite phase (indialite). This is in agreement with the findings of Redaoui et al. [38] that reported $1153{ }^{\circ} \mathrm{C}$ for formation of $\alpha$-cordierite phase. Yürüyen et al. [39] studied with mechanically activated talc-kaolinite-alumina ceramics system and reported that the $\alpha$-cordierite phase formed at about $1265{ }^{\circ} \mathrm{C}$. Furthermore, they stated that the mechanic activation process decreased the formation temperature of $\alpha$-cordierite phase.

Specific surface area and particle size for $D_{90}$ graph of the samples are presented in Fig. 5. Surface area increment with extended milling time was expected but contrary result was achieved. Determined increase of the specific surface area relates to aggregation and agglomeration phenomenon. The smaller particles gather to form larger entities. $D_{90}$ corresponds to the particle size at the $90 \%$ point on the cumulative distribution. As seen in Fig. 5, the particle size decreased with increasing mechanical activation duration.

SEM micrographs of the mechanically activated powder mixture are presented in Fig. 6. As shown in

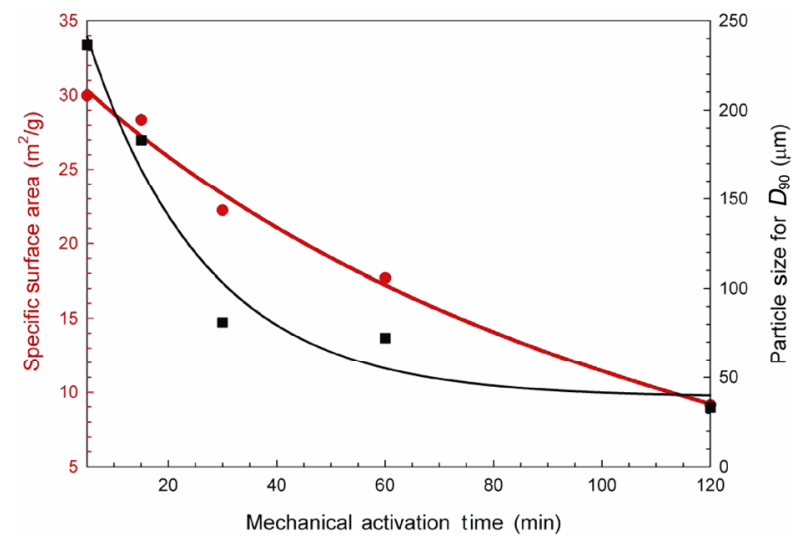

Fig. 5 Specific surface area and particle size for $D_{90}$ graph of the mechanically activated powder mixture for different milling time.
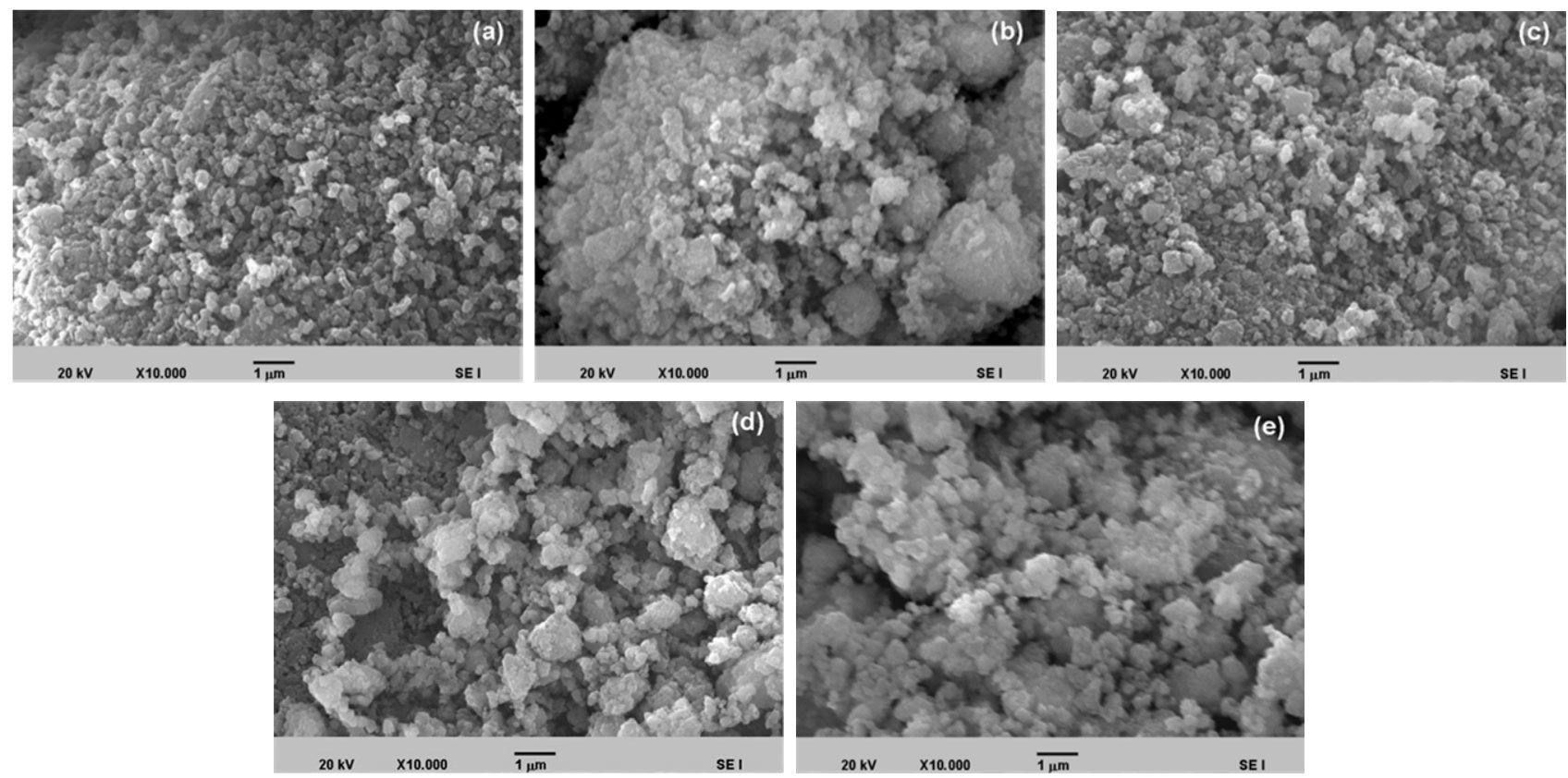

Fig. 6 SEM micrographs and particle size analysis of the mechanically activated powders for (a) 5, (b) 15, (c) 30, (d) 60, and (e) $120 \mathrm{~min}$. 
this figure, milling time affects particle size and shape. The particles have rounded morphology due to the erosive effects of the activation process. The irregular aggregate particles formed from the smaller particles with different particle size, occurred with increasing milling time.

Density change of the powder mixture as a function of the mechanical activation duration is shown in Fig. 7. The density of the mechanically activated powders decreased with increase in milling time. However, this decrease is not notable. The densities of the activated powders for 5,60 , and $120 \mathrm{~min}$ were $2.698,2.647$, and $2.637 \mathrm{~g} / \mathrm{cm}^{3}$, respectively.

\section{2 Characterization of sintered samples}

After $1 \mathrm{~h}$ milling time, amorphization degree of zeolite was $100 \%$. Therefore, mechanical activation duration for characterization studies after sintering was kept constant at $60 \mathrm{~min}$.

The XRD patterns of the sintered samples at different temperatures are presented in Fig. 8. Cordierite phase

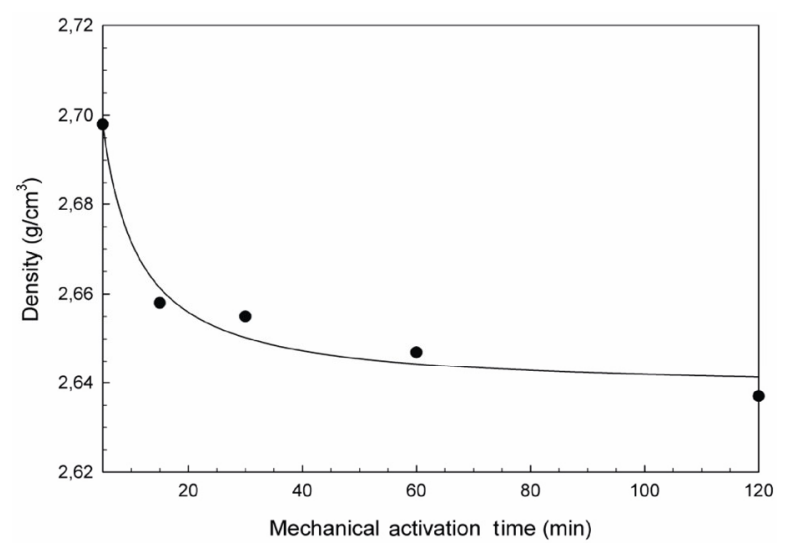

Fig. 7 Density change of the powder mixture as function of the mechanical activation duration.

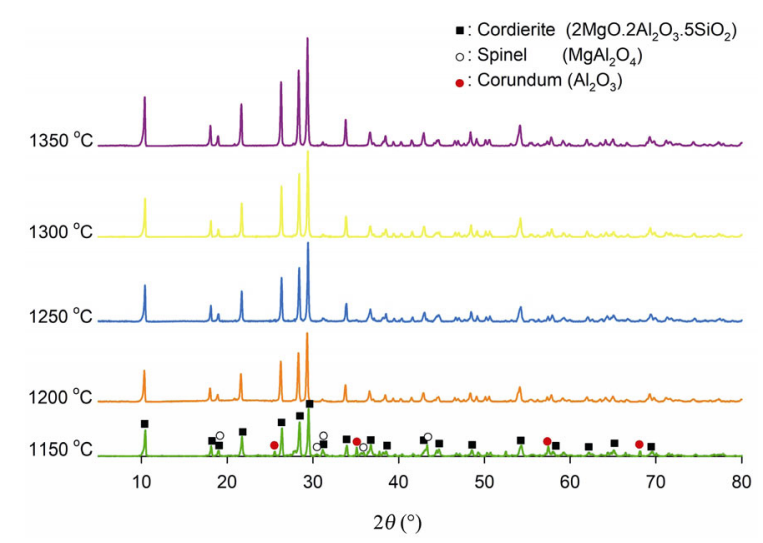

Fig. 8 XRD analysis of the samples sintered at different temperatures. was obtained at all temperatures, but purity of the samples related to other accompanying phases (corundum: JCPDS Card No. 10-0173, spinel: JCPDS Card No. 705187), and intensity of cordierite peak were different from each other. Cordierite peaks at all sintering temperature supported by two different JCPDS Cards (JCPDS Card Nos. 82-1884 and 13-0294). It was seen that intensity of cordierite peak became stronger with increase in sintering temperature. At $1250{ }^{\circ} \mathrm{C}, \alpha$-cordierite (indialite) phase at $2 \theta=10.45^{\circ}$ for (100), and spinel at $2 \theta=65.22^{\circ}$ for (440) were identified as most intense peaks of the related phases. In addition to cordierite phase, corundum and spinel $\left(\mathrm{MgAl}_{2} \mathrm{O}_{4}\right)$ were detected in samples sintered at $1150{ }^{\circ} \mathrm{C}$. So, it can be said that this temperature is not enough for sintering. The cordierite has very narrow sintering interval and this causes basic problems in production of cordierite ceramics [3]. They are not easily sintered without any sintering aids used to operate a liquid phase process close to their melting point $\left(1460{ }^{\circ} \mathrm{C}\right)$. Some attempts have been made to improve the ability to sinter cordierite. These studies mainly point to both the use of sintering aids and the development of new methods of synthesis [10]. The cordierite phase was obtained at $1150{ }^{\circ} \mathrm{C}$. Whereas, our previous studies on non-activated powders of zeolite+ $\mathrm{Al}_{2} \mathrm{O}_{3}+\mathrm{MgO}$ indicate that cordierite phase cannot be obtained at temperatures up to $1400{ }^{\circ} \mathrm{C}$ [26]. It might be originated from using the stored energy that was obtained from mechanical activation process in the particulate system. This stored energy had an important role for reactions at lower temperatures in respect to the increase in area of particle surface and utilization of stored energy [20]. Spinel structure was detected at all temperatures. Naskar and Chatterjee [40] stated that $\mathrm{MgAl}_{2} \mathrm{O}_{4}$ spinel is an intermediate phase that reacts with $\mathrm{SiO}_{2}$ to form cordierite structure. Banjuraizah et $a l$. [41] pointed the tendency of binary reaction between $\mathrm{Al}_{2} \mathrm{O}_{3}$ and $\mathrm{MgO}$ is higher than ternary reaction between $\mathrm{MgO}-\mathrm{Al}_{2} \mathrm{O}_{3}-\mathrm{SiO}_{2}$ and stated a reaction sequence as following:

$$
\begin{gathered}
\mathrm{MgO}+\mathrm{Al}_{2} \mathrm{O}_{3} \rightarrow \mathrm{MgAl}_{2} \mathrm{O}_{4} \\
2 \mathrm{MgAl}_{2} \mathrm{O}_{4}+5 \mathrm{SiO}_{2} \rightarrow 2 \mathrm{MgO} \cdot 2 \mathrm{Al}_{2} \mathrm{O}_{3} \cdot 5 \mathrm{SiO}_{2}
\end{gathered}
$$

In addition to this, glassy phase occurred in the samples that were sintered at different temperatures. If Table 1 is examined, it will be seen that zeolite contains silica, alumina, alkaline, and alkaline-earth oxides. In this case, the sintering mechanism is liquid phase sintering 
and the formation of a glassy phase is inevitable. However, glassy phase quantity decreased with increasing sintering temperature. From the XRD result it can be said that, our optimum sintering temperature is $1250{ }^{\circ} \mathrm{C}$ and it is lower than other studies in respect to cordierite formation $[4,5,7,39]$.

Figure 9 illustrates SEM micrographs of the polished and etched surface of samples sintered at various temperatures for $1 \mathrm{~h}$. As seen, microstructures consist of larger grains and smaller grains. The smaller grains settled on larger grains. Quantity and size of the pores increased with increasing sintering temperature. It is known that liquid phase sintering occurs at three stages: particle rearrangement, dissolution and precipitation, and solid state sintering. In solution and re-precipitation process, smaller particles dissolve from areas where they are in contact. The dissolved particles are carried away from the contact areas and re-precipitate on larger particles $[22,42]$. EDS analyses of the sample sintered at $1250{ }^{\circ} \mathrm{C}$ for $1 \mathrm{~h}$ are presented in Fig. 10. As seen, both smaller grains and larger grains exhibit close composition.

AFM images of the sintered samples and mean grain size variation as a function of sintering temperature are presented in Fig. 11. As expected, the grains coarsened at high temperatures. The mean grain size changes between 1.34 and $1.96 \mu \mathrm{m}$ depending on temperature.

The sintering behavior of the samples was evaluated by the determination of the linear shrinkage, density, and apparent porosity as a function of the sintering
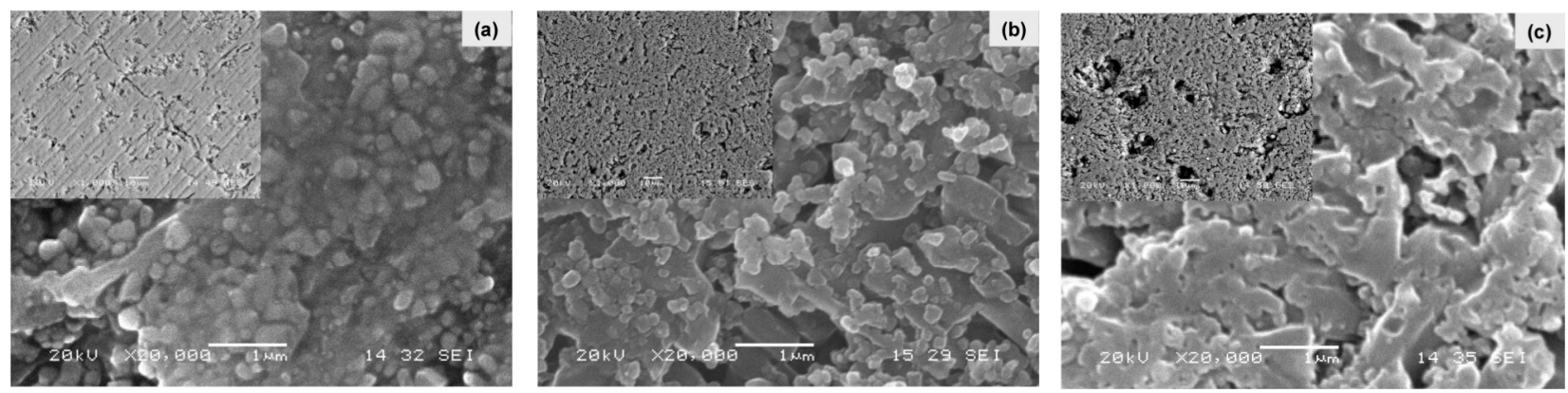

Fig. 9 SEM micrographs of the samples sintered at (a) 1150, (b) 1250 , (c) $1350{ }^{\circ} \mathrm{C}$ for $1 \mathrm{~h}$.
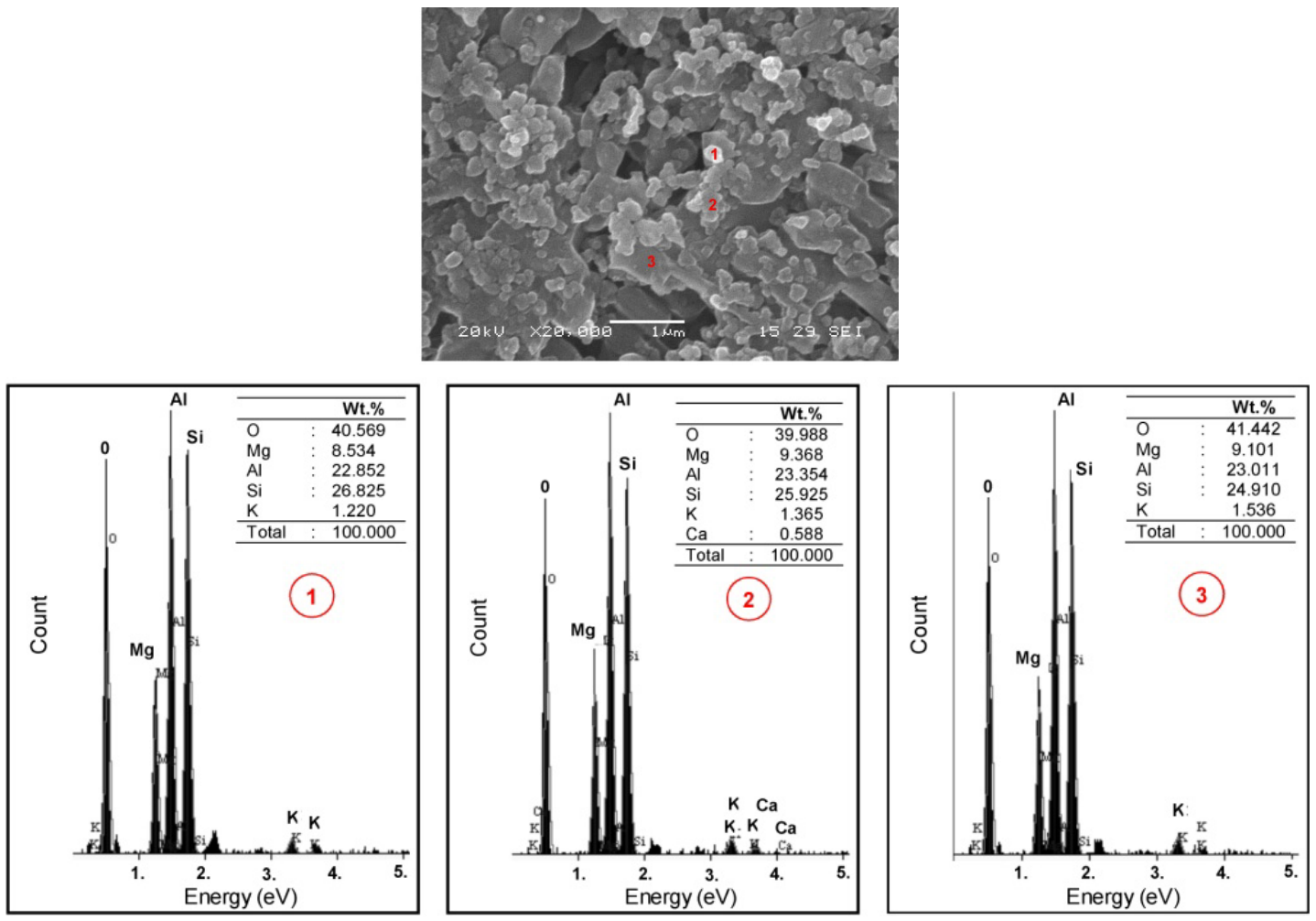

Fig. 10 SEM micrograph and EDS analysis of the samples sintered at $1250{ }^{\circ} \mathrm{C}$ for $1 \mathrm{~h}$. 

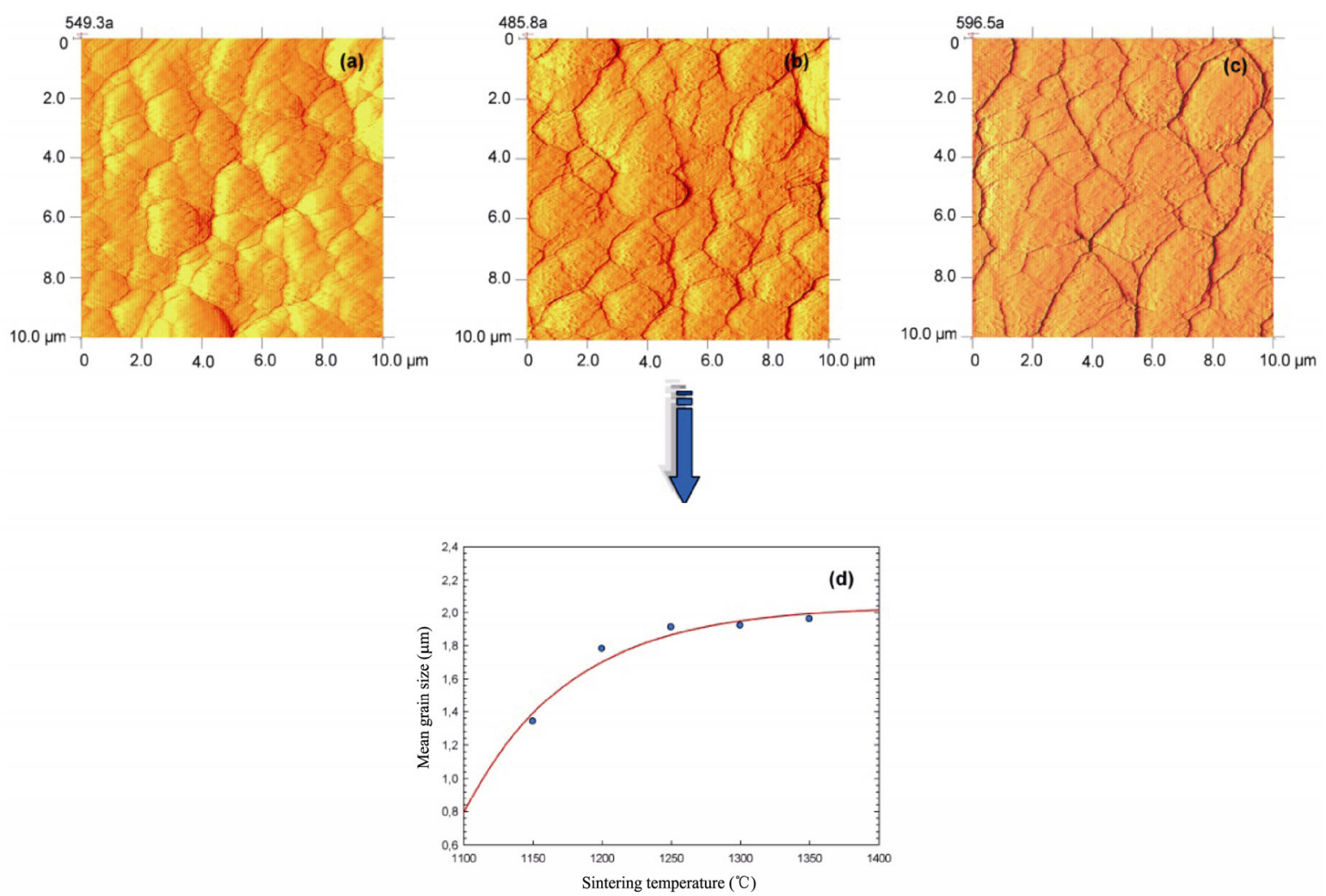

Fig. 11 AFM images of the samples sintered at (a) 1150 , (b) 1200 , (c) $1350{ }^{\circ} \mathrm{C}$ and (d) mean grain size variation as a function of sintering temperature.

temperature. The obtained results are presented in Fig. 12. As observed from the graphics, the apparent porosity value increased while the linear shrinkage and density values decreased with increasing sintering temperature. This event can be explained as follows: quantity of glassy phase which is a metastable phase decreased with increasing sintering temperature. The decomposition of oxides allowing the release of oxygen took place at higher temperatures and swelling occurred at samples. Therefore, apparent porosity value increased while the linear shrinkage and density decreased. The density values changed between 2.31 and $2.69 \mathrm{~g} / \mathrm{cm}^{3}$ depending on sintering temperature. Fotoohi and Blackburn [43] indicated that the theoretical density of cordierite is $2.6 \mathrm{~g} / \mathrm{cm}^{3}$ and the density of the samples produced from mechanically activated kaolin/talc/ boehmite powders and sintered at $1300{ }^{\circ} \mathrm{C} / 2 \mathrm{~h}$ was $2.33 \mathrm{~g} / \mathrm{cm}^{3}$. Neto and Moreno [19] reported that the density of samples produced from mechanically activated kaolin/talc/alumina powders and sintered at $1350{ }^{\circ} \mathrm{C} / 1 \mathrm{~h}$
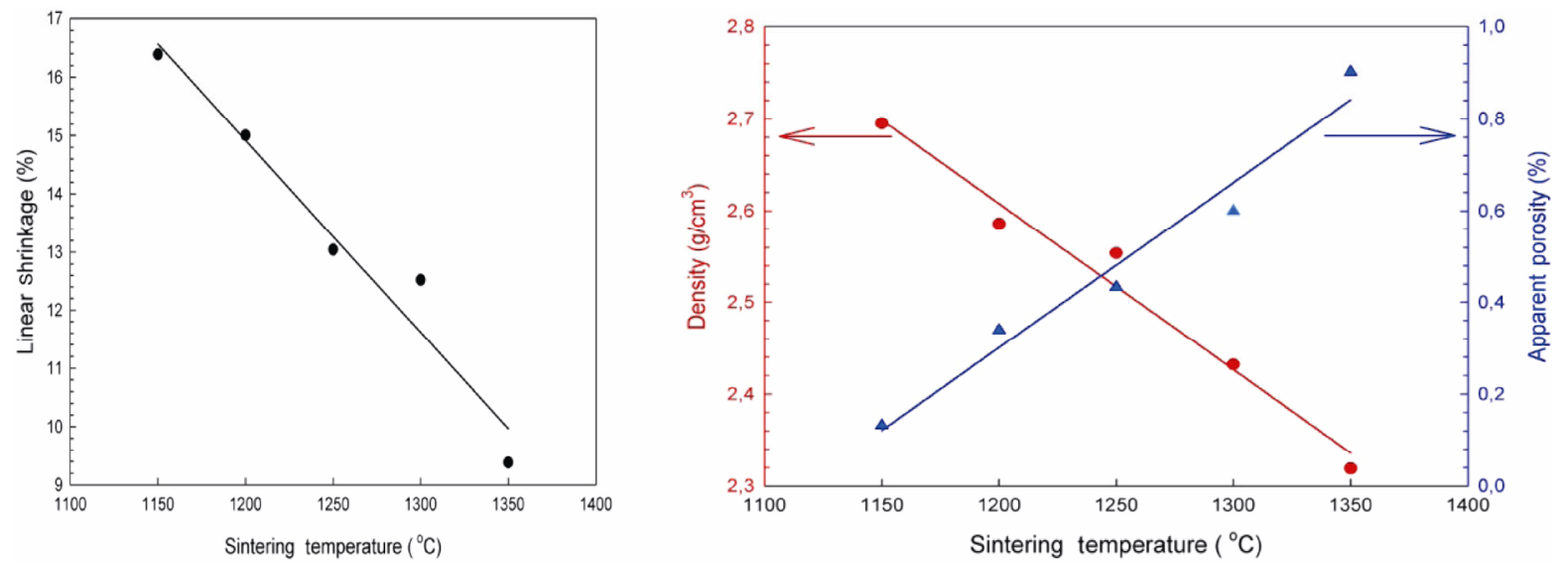

Fig. 12 (a) Linear shrinkage, (b) density and apparent porosity of sintered samples as a function of the sintering temperature. 
was $2.58 \mathrm{~g} / \mathrm{cm}^{3}$. Thus, the results obtained in the present study are in good agreement with obtained results in the literature.

\section{Conclusions}

Zeolite $+\mathrm{Al}_{2} \mathrm{O}_{3}+\mathrm{MgO}$ powder mixtures prepared according to the cordierite stoichiometry were mechanically activated for $5,15,30,60$, and $120 \mathrm{~min}$. Then, the activated powders for $60 \mathrm{~min}$ were sintered at 1150 , $1200,1250,1300$, and $1350{ }^{\circ} \mathrm{C}$ for $1 \mathrm{~h}$.

A very dense material with a high content of cordierite was produced using zeolite as raw material.

The produced samples contain cordierite, spinel, and some glassy phases. The intensity of cordierite peak increased with increasing sintering temperature.

Microstructural investigations of the sintered samples revealed various features, including blocky grains, nodular grains, and porosity. The grains coarsened with increasing sintering temperature.

The apparent porosity value increased while the linear shrinkage and density values decreased with increasing sintering temperature.

From the results optimum sintering temperature was determined as $1250{ }^{\circ} \mathrm{C}$. Dense material was produced at a temperature as low as $1250{ }^{\circ} \mathrm{C}$ using zeolite as raw material.

\section{Acknowledgements}

This research was performed within the project 2010-0108-014. We thank the Commission for Scientific Research Projects of Sakarya University for funding this project.

\section{References}

[1] Hayati EZ, Moradi OM, Kakroudi MG. Investigation the effect of sintering temperature on Young's modulus evaluation and thermal shock behavior of a cordierite-mullite based composite. Mater Design 2013, 45: 571-575.

[2] Obradović N, Đorđević N, Filipović S, et al. Influence of mechanochemical activation on the sintering of cordierite ceramics in the presence of $\mathrm{Bi}_{2} \mathrm{O}_{3}$ as a functional additive. Powder Technol 2012, 218: 157-161.

[3] Acimovic Z, Pavlovic L, Trumbulovic L, et al. Synthesis and characterization of the cordierite ceramics from nonstandard raw materials for application in foundry. Mater Lett 2003, 57: 2651-2656.

[4] Yamuna A, Johnson R, Mahajan YR, et al. Kaolin-based cordierite for pollution control. J Eur Ceram Soc 2004, 24: 65-73.

[5] Ogiwara T, Noda Y, Shoji K, et al. Solid state synthesis and its characterization of high density cordierite ceramics using fine oxide powders. J Ceram Soc Jpn 2010, 118: 246-249.

[6] Association of the German Ceramic Industry. Breviary Technical Ceramics. Fahner Verlag, Lauf, 2004.

[7] Goren R, Ozgur C, Gocmez H. The preparation of cordierite from talc, fly ash, fused silica and alumina mixtures. Ceram Int 2006, 32: 53-56.

[8] Ghitulica C, Andronescu E, Nicola O, et al. Preparation and characterization of cordierite powders. J Eur Ceram Soc 2007, 27: 711-713.

[9] González-Velasco JR, Ferret R, López-Fonseca R, et al. Influence of particle size distribution of precursor oxides on the synthesis of cordierite by solid-state reaction. Powder Technol 2005, 153: 34-42.

[10] Camerucci MA, Urretavizcaya G, Cavalieri AL. Sintering of cordierite based materials. Ceram Int 2003, 29: 159-168.

[11] Maier N, Nickel KG, Engel C, et al. Mechanisms and orientation dependence of the corrosion of single crystal cordierite by model diesel particulate ashes. $J$ Eur Ceram Soc 2010, 30: 1629-1640.

[12] Kurama S, Kurama H. The reaction kinetics of rice husk based cordierite ceramics. Ceram Int 2008, 34: 269-272.

[13] Azín NJ, Camerucci MA, Cavalieri AL. Crystallisation of non-stoichiometric cordierite glasses. Ceram Int 2005, 31: 189-195.

[14] Đorđević NG, Jovanić PB. Influence of mechanical activation on electrical properties of cordierite ceramics. Sci Sinter 2008, 40: 47-53.

[15] Krivoshapkina EF, Krivoshapkin PV, Vedyagin AA. Synthesis of $\mathrm{Al}_{2} \mathrm{O}_{3}-\mathrm{SiO}_{2}-\mathrm{MgO}$ ceramics with hierarchical porous structure. $J A d v$ Ceram 2017, 6: 11-19.

[16] Krivoshapkina EF, Vedyagin AA, Krivoshapkin PV, et al. Carbon monoxide oxidation over microfiltration ceramic membranes. Pet Chem 2015, 55: 901-908.

[17] Bejjaoui R, Benhammou A, Nibou L, et al. Synthesis and characterization of cordierite ceramic from Moroccan stevensite and andalusite. Appl Clay Sci 2010, 49: 336-340.

[18] Shi Z. Preparation of cordierite ceramic using mixtures of $\mathrm{Ce}^{4+}$-modified amorphous powder and oxide powders. $J$ Rare Earth 2006, 24: 263-265.

[19] Neto JBR, Moreno R. Effect of mechanical activation on the rheology and casting performance of kaolin/talc/alumina suspensions for manufacturing dense cordierite bodies. Appl Clay Sci 2008, 38: 209-218.

[20] Balaz P. Mechanochemistry in Nanoscience and Minerals Engineering. Springer-Verlag, Berlin, 2008.

[21] Antsiferov VN, Porozova SE. Enhancing strength of highporous cordierite ceramics by mechanochemical activation of the charge. Russ J Non-ferrous Metals 2007, 48: 456460.

[22] Tamborenea S, Mazzoni AD, Aglietti EF. Mechanochemical 
activation of minerals on the cordierite synthesis. Thermochim Acta 2004, 411: 219-224.

[23] German RM. Powder Metallurgy and Particulate Materials Processing. Princeton, USA: Metal Powder Industries Federation, 2005.

[24] Marinković ZV, Nikolić N, Stojanović J, et al. The influence of mechanical activation of starting components on kinetics of cordierite formation. J Min Metall B 2001, 37: 67-75.

[25] Goren R, Gocmez H, Ozgur C. Synthesis of cordierite powder from talc, diatomite and alumina. Ceram Int 2006, 32: 407-409.

[26] Tunç T, Demirkıran AŞ. The effects of mechanical activation on the sintering and microstructural properties of cordierite produced from natural zeolite. Powder Technol 2014, 260: 7-14.

[27] Weitkamp J. Zeolites and catalysis. Solid State Ionics 2000, 131: $175-188$.

[28] Demirkiran AŞ, Artir R, Avci E. Effect of natural zeolite addition on sintering kinetics of porcelain bodies. $J$ Mater Process Tech 2008, 203: 465-470.

[29] Chandrasekhar S, Pramada PN. Thermal studies of low silica zeolites and their magnesium exchanged forms. Ceram Int 2002, 28: 177-186.

[30] Karadag D, Koc Y, Turan M, et al. A comparative study of linear and non-linear regression analysis for ammonium exchange by clinoptilolite zeolite. J Hazard Mater 2007, 144: 432-437.

[31] Guczia L, Kiricsi I. Zeolite supported mono- and bimetallic systems: Structure and performance as $\mathrm{CO}$ hydrogenation catalysts. Appl Catal A 1999, 186: 375-394.

[32] Vander Voort GF. Metallography-Principles and Practice. McGraw-Hill, 1984.

[33] Kambale KR., Kulkarni AR, Venkataramani N. Grain growth kinetics of barium titanate synthesized using conventional solid state reaction route. Ceram Int 2014, 40 : $667-673$.

[34] Tromans D, Meech JA. Enhanced dissolution of minerals: stored energy, amorphism and mechanical activation. Miner Eng 2001, 14: 1359-1377.

[35] Charkhi A, Kazemian H, Kazemeini M. Optimized experimental design for natural clinoptilolite zeolite ball milling to produce nano powders. Powder Technol 2010, 203: 389-396.

[36] Yang Z, Liu Y, Yu C, et al. Ball-milled NaA zeolite seeds with submicron size for growth of $\mathrm{NaA}$ zeolite membranes. J Membrane Sci 2012, 392-393: 18-28.

[37] $\mathrm{Su} \mathrm{X}, \mathrm{Du} \mathrm{X}, \mathrm{Li} \mathrm{S}$. Synthesis of $\mathrm{MgAl}_{2} \mathrm{O}_{4}$ spinel nanoparticles using a mixture of bayerite and magnesium sulfate. J Nanopart Res 2010, 12: 1813-1819.

[38] Redaoui D, Sahnoune F, Heraiz M, et al. Phase formation and crystallization kinetics in cordierite ceramics prepared from kaolinite and magnesia. Ceram Int 2018, 44: 3649-3657.

[39] Yürüyen S, Toplan N, Yildiz K, et al. The non-isothermal kinetics of cordierite formation in mechanically activated talc-kaolinite-alumina ceramics system. $J$ Therm Anal Calorim 2016, 125: 803-808.

[40] Naskar MK, Chatterjee M. A novel process for the synthesis of cordierite $\left(\mathrm{Mg}_{2} \mathrm{Al}_{4} \mathrm{Si}_{5} \mathrm{O}_{18}\right)$ powders from rice husk ash and other sources of silica and their comparative study. J Eur Ceram Soc 2004, 24: 3499-3508.

[41] Banjuraizah J, Mohamad H, Ahmad ZA. Effect of excess $\mathrm{MgO}$ mole ratio in a stoichiometric cordierite $\left(2 \mathrm{MgO} \cdot 2 \mathrm{Al}_{2} \mathrm{O}_{3} \cdot 5 \mathrm{SiO}_{2}\right)$ composition on the phase transformation and crystallization behavior of magnesium aluminum silicate phases. Int J Appl Ceram Technol 2011, 8: $637-645$.

[42] Hamzawy EM, El-Kheshen AA, Zawrah MF. Densification and properties of glass/cordierite composites. Ceram Int 2005, 31: 383-389.

[43] Fotoohi B, Blackburn S. Effects of mechanochemical processing and doping of functional oxides on phase development in synthesis of cordierite. J Eur Ceram Soc 2012, 32: 2267-2272.

Open Access The articles published in this journal are distributed under the terms of the Creative Commons Attribution 4.0 International License (http://creativecommons.org/licenses/by/4.0/), which permits unrestricted use, distribution, and reproduction in any medium, provided you give appropriate credit to the original author(s) and the source, provide a link to the Creative Commons license, and indicate if changes were made. 